\title{
KUALITAS PAPAN KOMPOSIT DARI LIMBAH FINIR KAYU LAPIS BERDASARKAN UKURAN PARTIKEL DAN WAKTU PENGEMPAAN DENGAN MENGGUNAKAN PEREKAT LIMBAH PLASTIK POLIPROPILENA
}

(The quality of composite boards from plywood veneer waste base on particle sizes and pressing time using the polypropylene plastic waste adhesives)

\author{
Alfonsus Rodriquez Caesario Tajaanglaing, Ahmad Yani, Fathul Yusro \\ Fakultas Kehutanan Universitas Tanjungpura Pontianak. Jl. Daya Nasional Pontianak 78124 \\ Email: alfonrodriquez@gmail.com
}

\begin{abstract}
This study aims to analyze the quality of composite boards from plywood veneers waste and polypropylene plastic waste adhesives base on particle sizes, pressing times, and both of interaction towards physical and mechanical properties also to obtain the particle sizes and pressing time properly with the result that produce the qualified standard boards of JIS A 59082003. This research carried out at the wood workshop, laboratory of technology and processing of woods (the faculty of forestry, university of Tanjungpura), and the laboratory of PT. Duta Pertiwi Nusantara. The materials used in this study were plywood veneers waste and polypropylene plastic by 50\% : 50\% comparison. The research method was utilized the completely randomized factorial design by two treatment factors. Factor A was particle sizes that consisting of 6 mesh, 8 mesh, and 10 mesh. Factor B was pressing time that consisting of 10 minutes, 15 minute, and 20 minutes. Composite boards were created by $30 \times 30 \times 1$ size in centimetres by means the density target was $0,7 \mathrm{gr} / \mathrm{cm}^{3}$. The pressing was done by hot press in $180^{\circ} \mathrm{C}$ temperature and composite boards conditioning for 14 days. The results of this study showed that the density, water absorption, thickness, Modulus of Repture (MOR), internal bonding, holding strength of screws in the composite boards have been qualified the standard of JIS A 5908-2003. While, the water contents and Modulus of Elasticity (MOE) testing were not qualified the standard of JIS 5908-2003. The treatment that produce the optimum composite boards which quality JIS A 5908-2003 standard was on the 8 mesh particle size treatment by means of 15 minutes pressing time.
\end{abstract}

Keywords: Composite Board, Particle Size, Polypropylene Plastics, Pressing Time, Veneers Waste.

\section{PENDAHULUAN}

Kayu merupakan kebutuhan pokok dalam pembuatan kontruksi bangunan yang dapat menyebabkan penggunaan kayu semakin meningkat, sedangkan pasokan kayu dari alam sangatlah terbatas dan juga tidak sesuai dengan kebutuhan yang diperlukan. Kebutuhan kayu yang dipergunakan sebagai bahan baku industri sebanyak 49,1 juta $\mathrm{m}^{3}$ per tahun, sedangkan Departemen Kehutanan memberi jatah produksi pada tahun 2012 sebanyak $9,1 \mathrm{~m}^{3}$ per tahun sehingga kebutuhan kayu nasional tidak terpenuhi (Menteri Kehutanan, 2013). Keadaan ini berdampak pada makin sulitnya industri memperoleh pasokan bahan baku kayu baik secara kualitas dan kuantitas. Hal tersebut membuat industri 
dan peneliti terus berupaya mengembangkan penemuan baru guna mengatasi masalah tersebut.

Industri dalam pengolahan kayu dapat menghasilkan limbah, salah satunya pada industri kayu lapis yang menghasilkan limbah finir dan industri penggergajian yang menghasilkan limbah berupa serbuk kayu. Produksi kayu lapis di Indonesia sebesar 4,61 juta $\mathrm{m}^{3}$ per tahun dengan asumsi limbah berdasarkan perbandingan output dengan input yang akan dihasilkan berjumlah $60 \%$ dari total bahan baku sehingga diperkirakan limbah yang akan dihasilkan per tahun mencapai 2,8 juta $\mathrm{m}^{3}$ (Departemen Kehutanan, 1990 dalam Sinaga et al. 2016). Selama ini pemanfaatan limbah industri kayu tersebut sangatlah minim. Sehingga potensi limbah yang besar tersebut belum dimanfaatkan secara maksimal oleh industri. Selain adanya limbah kayu yang kurang dimanfaatkan, disisi lain limbah plastik termasuk salah satu buangan atau sampah dari masyarakat yang tidak dapat terurai oleh alam sehingga dapat mengotori lingkungan sekitar.

Kegiatan pengolahan sampah menjadi sebuah produk hanya sekitar 5\%, sedangkan sisanya dibuang ke Tempat Pembuangan Akhir (TPA), sementara lahan TPA sangat terbatas. Komposisi sampah di TPA selain sampah organik $70 \%$ terdapat pula sampah non organik berupa plastik $14 \%$. Berdasarkan data Kementrian Lingkungan Hidup dan Kehutanan, total jumlah sampah Indonesia di tahun 2019 akan mencapai 68 juta ton dan sampah plastik di perkirakan mencapai 9,52 juta ton (Purwaningrum, 2016). Karena pemanfaatan limbah industri kayu lapis masih kurang optimal dan limbah plastik semakin meningkat, sehingga dalam penelitian ini peneliti mencoba untuk memanfaatkannya sebagai bahan baku pembuatan papan komposit.

Maloney (1993), papan komposit merupakan istilah umum dari berbagai produk pembuatan papan dari dua bahan baku atau lebih berupa partikel atau potongan kecil kayu dengan campuran perekat. Komposit terdiri dari 2 bagian utama yaitu Matriks sebagai perekat dan Filler sebagai pengisi. Pada penelitian ini limbah plastik sebagai Matriks dan limbah finir kayu lapis sebagai Filler, dan faktor yang digunakan adalah ukuran partikel dan waktu kempa.

Ukuran partikel yang digunakan dalam penelitian ini adalah 6 mesh, 8 mesh dan 10 mesh yang diperoleh dari potongan - potongan kecil limbah finir kayu lapis. Mengacu pada penelitian Maulana et al. (2015), tentang karakteristik papan partikel dari batang mengkuang (Pandanus atrocarpus Griff) dengan perekat plastik polipropilena menunjukkan bahwa partikel kasar 6 mesh mempunyai perlakuan terbaik untuk sifat fisik dan mekanik papan komposit. Waktu pengempaan yang digunakan dalam penelitian ini adalah 10 menit, 15 menit dan 20 menit. Mengacu pada penelitian Erniwati et al. (2015), tentang pengaruh suhu dan waktu kempa terhadap kualitas papan komposit berlapis anyaman 
bambu, dengan perekat plastik polipropilena menunjukkan bahwa waktu pengempaan 15 menit menghasilkan papan yang lebih baik dari papan yang dikempa selama 10 menit.

Penelitian terdahulu menggunakan bahan non kayu sebagai pengisi dan perekat plastik polipropilena. Untuk itu, pada penelitian ini peneliti memanfaatkan limbah finir kayu lapis dan limbah plastik polipropilena sebagai perekat thermoplastik dengan perlakuan ukuran partikel dan waktu kempa. Tujuan dari penelitian ini untuk menganalisis kualitas papan komposit dari limbah finir kayu lapis berdasarkan ukuran partikel dan waktu pengempaan dengan menggunakan perekat limbah plastik polipropilena (PP) serta interaksi keduanya terhadap sifat fisik dan mekanik papan komposit, dan juga mendapatkan ukuran partikel dan waktu pengempaan yang tepat sehingga menghasilkan papan komposit yang baik dan memenuhi standar JIS A 5908 : 2003.

\section{METODE PENELITIAN}

Penelitian ini dilakukan ditiga tempat, yaitu di Wood Workshop untuk pengolahan bahan baku dan laboratorium Pengolahan Kayu Fakultas Kehutanan untuk persiapan sampel dan pengujian sifat fisik serta laboratorium Duta Pertiwi Nusantara (DPN) untuk pembuatan sampel dan menguji sifat mekanik. Penelitian ini dilakukan selama \pm 3 bulan mulai bulan September s.d November 2018 dari persiapan, pengerjaan, pengujian hingga pengolahan data. Bahan yang dipergunakan dalam penelitian ini adalah limbah finir kayu lapis dan plastik polipropilena. Alat yang digunakan adalah bak plastik, oven, hammer mill, plastik peking, kamera digital, almunium foil, terpal, plat seng, timbangan, neraca analitik, table saw, kaliper, gunting, cetakan dengan ukuran $30 \mathrm{~cm}$ x $30 \mathrm{~cm}$, termometer, mesin kempa, mesh screen dan universal testing machine (UTM).

\section{Persiapan Bahan Baku}

Limbah finir kayu lapis dipotong kecil-kecil secara manual agar mudah digiling dengan hammer mill. Partikel yang telah di hammer mill diayak menggunakan mesh screen untuk mendapatkan partikel yang tertahan disaringan 6 mesh, 8 mesh dan 10 mesh, kemudian ditimbang dan dikeringkan dalam oven dengan suhu $60^{\circ} \mathrm{C}$ hingga mencapai kadar air $\pm 5 \%$ (Maulana et al. 2015). Limbah plastik yang dipotong kecil - kecil berukuran kurang lebih 1 $\mathrm{cm}$. Limbah plastik polipropilena dan limbah finir dengan perbandingan partikel $50 \%$ : $50 \%$ plastik, kemudian dicampurkan sehingga homogen.

\section{Pembuatan Papan Komposit}

Semua

bahan ditimbang berdasarkan perhitungan komposisi bahan yang sudah ditetapkan, kemudian dilakukan pencampuran partikel dan plastik dengan perbandingan 50\%: 50\% yang dilakukan secara manual. Bahanbahan yang sudah dicampurkan tersebut dimasukkan ke dalam cetakan berukuran $30 \mathrm{~cm}$ x $30 \mathrm{~cm}$ x $1 \mathrm{~cm}$ yang telah diberi alas plat seng, kemudian dimasukan bahan yang telah dicampur secara homogen. Selanjutnya permukaan 
ditutup dengan tutupan cetakan dan diberikan pra penekanan selama \pm 2 menit bahan contoh uji menjadi rapat agar tidak hancur setelah tutupan cetakan diangkat. Kemudian cetakan diangkat secara perlahan dan pada sisi kiri dan kanan cetakan diletakkan plat baja setebal $1 \mathrm{~cm}$ sebagai penahan untuk mendapatkan ketebalan yang diinginkan. Papan dimasukkan kedalam mesin kempa pada suhu $180^{\circ} \mathrm{C}$ dengan tekanan $\pm 25 \mathrm{~kg} / \mathrm{cm}^{2}$ (Sumimi et al. 2016) dengan waktu pengempaan yang sudah ditetapkan yaitu 10 menit, 15 menit, 20 menit. Kemudian setelah dikempa panas diangkat menggunakan penjepit dan plat seng didinginkan menggunakan kain basah agar bahan tidak menempel pada plat seng setelah itu dibuka plat seng dari lembaran papan. Pengkondisian dilakukan selama 14 hari pada suhu

HASIL DAN PEMBAHASAN

\section{Sifat Fisik Papan Komposit}

a. Kerapatan

Secara keseluruhan nilai kerapatan papan komposit yang dihasilkan dapat memenuhi standar JIS A 5908 - 2003 kamar untuk menyeragamkan kadar air dan menghilangkan tegangan sisa yang terbentuk selama proses pengempaan panas, agar kondisi papan komposit sesuai dengan suhu ruangan. Sampel dipotong berdasarkan sistem JIS (Japanese Industrial Standar) A 5908 : 2003. Untuk mengetahui kualitas papan komposit maka dilakukan pengujian sifat fisik dan sifat mekanik seperti kerapatan, kadar air, daya serap air, pengembangan tebal, MOE, MOR, internal bonding dan kuat pegang sekrup serta menggunakan metode percobaan faktorial Rancangan Acak Lengkap (RAL) yang hasil perhitungan dianalisis menggunakan SPSS 25. Parameter yang diuji untuk mewakili mutu papan komposit yang dilakukan berdasarkan standar JIS A 5908 : 2003.

yang mensyaratkan nilai kerapatan papan komposit $0,4-0,9 \mathrm{~g} / \mathrm{cm}^{3}$. Nilai rerata kerapatan papan komposit yang dihasilkan bervariasi antara 0,6493 $\mathrm{g} / \mathrm{cm}^{3}$ sampai $0,7747 \mathrm{~g} / \mathrm{cm}^{3}$.

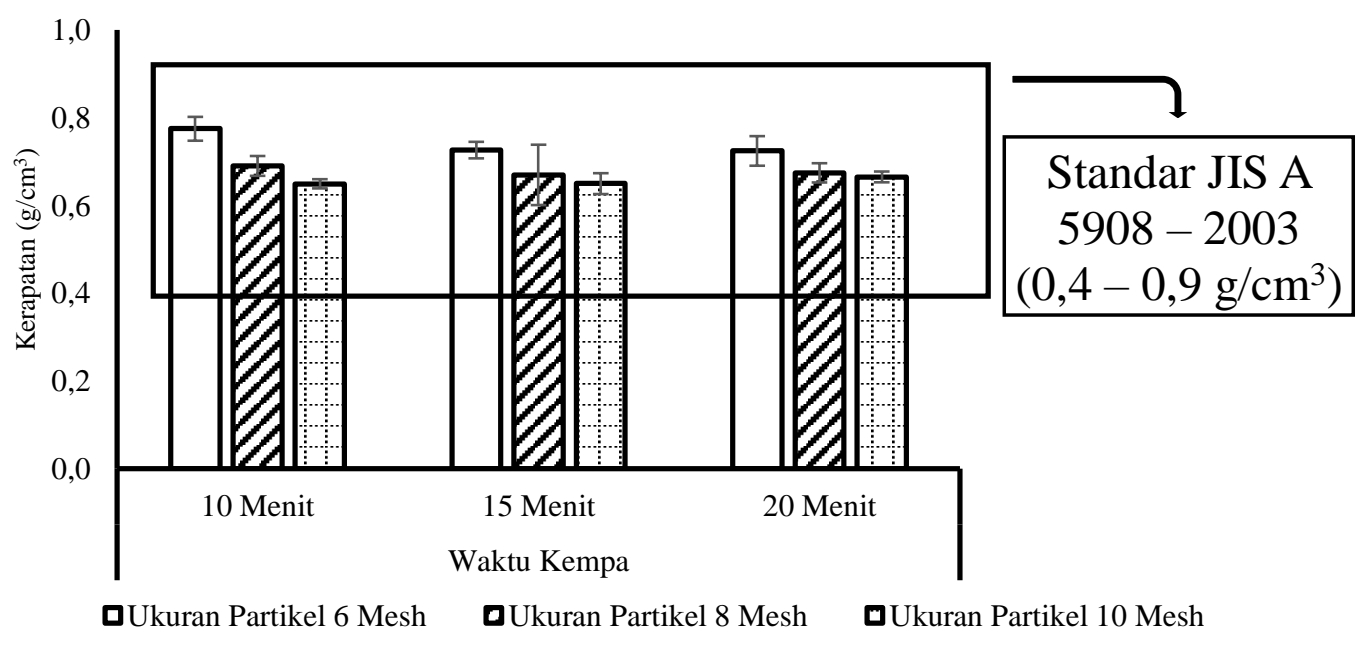




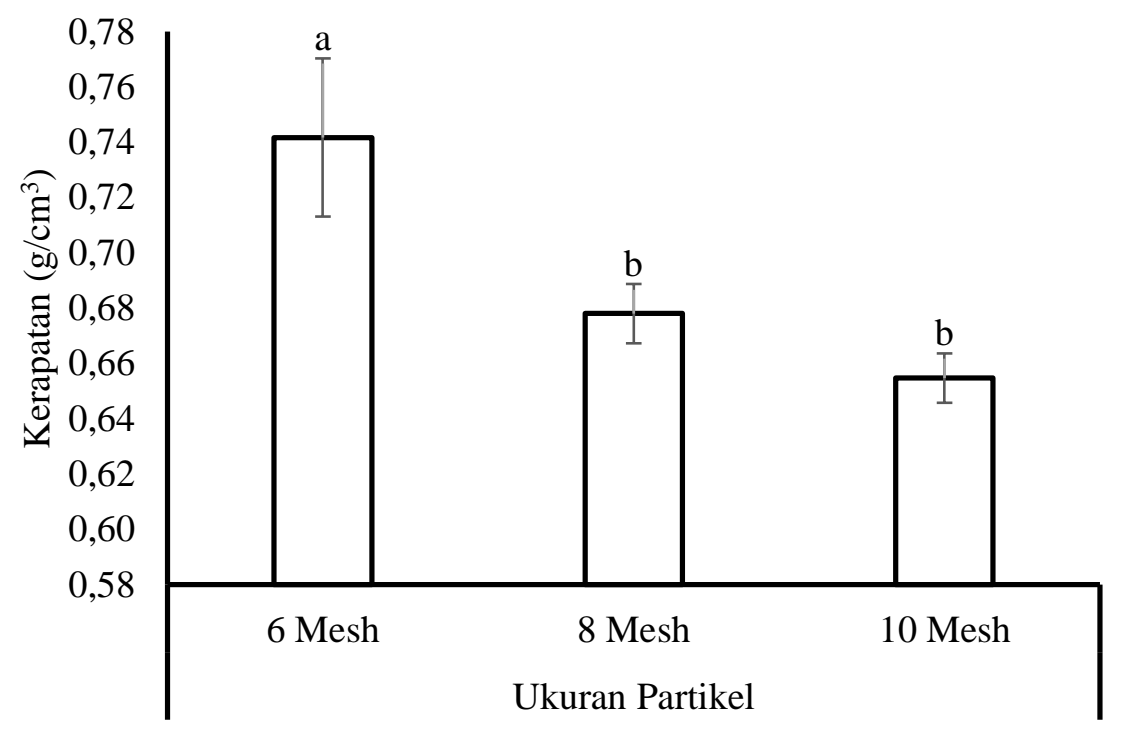

$\mathrm{b}$

Gambar 1. a. Kerapatan \pm SD papan komposit limbah finir kayu lapis berdasarkan ukuran partikel dan waktu kempa serta; b. Uji Beda Nyata untuk pengaruh perlakuan ukuran partikel (a. Density $\pm S D$ composite finir board based on particle size and time of press and; $b$. Real Difference Test for particle size treatment effects)

Secara umum hasil penelitian nilai kerapatan menunjukkan bahwa ukuran partikel 6 mesh memiliki kualitas yang lebih baik (Gambar 1a). Hasil uji BNJ kerapatan berdasarkan ukuran partikel menunjukkan bahwa perlakuan ukuran partikel 6 mesh berbeda sangat nyata terhadap perlakuan ukuran partikel 8 mesh dan 10 mesh. Sedangkan perlakuan 8 mesh tidak berbeda nyata dengan perlakuan perlakuan 10 mesh (Gambar 1b). Hal ini diduga ukuran partikel dapat mempengaruhi kualitas papan komposit, sehingga partikel yang lebih kasar memiliki kualitas yang lebih baik dari pada ukuran partikel halus. Hal ini sejalan dengan penelitian Maulana et al.
(2015) bahwa perlakuan terbaik terhadap sifat fisik dan mekanik papan partikel adalah ukuran partikel kasar. Menurut Abdurachman dan Hadjib (2011), pada papan komposit yang menggunakan ukuran partikel kasar akan menghasilkan papan yang lebih baik dibandingkan dengan papan yang menggunakan partikel halus.

b. Kadar Air

Secara umum papan komposit yang dihasilkan pada penelitian ini tidak memenuhi standar JIS A 5908 - 2003 yang mensyaratkan nilai kadar air sebesar 5 - 13\%. Nilai kadar air untuk setiap perlakuan berkisar antara 2,8480 $3,2618 \%$. 


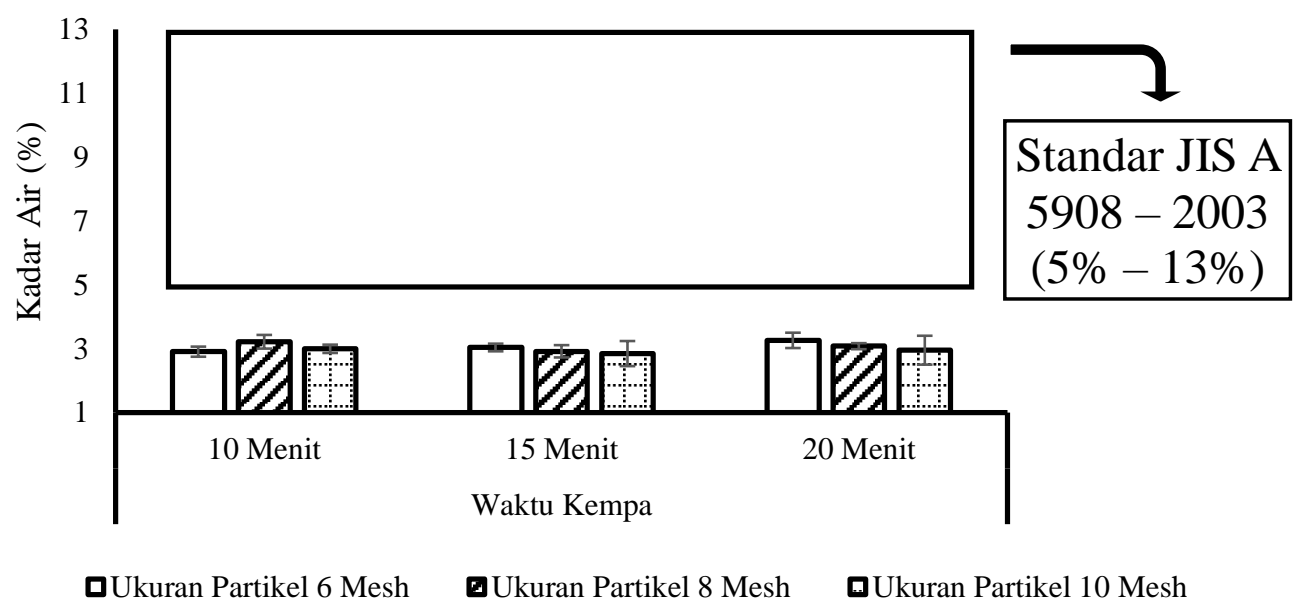

Gambar 2. Kadar air \pm SD papan komposit berdasarkan ukuran partikel dan waktu kempa (Water content $\pm S D$ composite board based on particle size and press time)

Penelitian ini nilai kadar air tidak menyerap uap air dari lingkungan memenuhi standar JIS A 5908 - 2003 diduga bahwa pada awal penyiapan bahan partikel mempunyai kadar air di bawah $5 \%$ dan pada umumnya papan komposit yang menggunakan bahan plastik memiliki kadar air yang lebih rendah, karena adanya perlakuan panas dan pengunaan plastik sebagai perekat (Massijaya et al. 1999) sehingga memungkinkan papan komposit memiliki penyerapan air yang lebih rendah. Rendahnya kadar air pada papan komposit tersebut disebabkan plastik polipropilena daur ulang yang digunakan sebagai perekat bersifat hidrofobik, sehingga papan komposit tidak mudah (Setyawati et al. 2008). Berdasarkan hasil analisis keragaman diketahui bahwa perlakuan ukuran partikel dan waktu kempa tidak berpengaruh terhadap kadar air dari papan komposit. c. Daya Serap Air

Nilai kadar air papan komposit untuk setiap perlakuan berkisar antara $20,5137 \%$ - 37,2276\%. Standar JIS A 5908 - 2003 tidak mensyaratkan daya serap air, namun pengujian ini tetap dilakukan mempertimbangkan ketahanan papan komposit terhadap penyerapan air sehingga dapat layak dipergunakan untuk interior dan eksterior. 


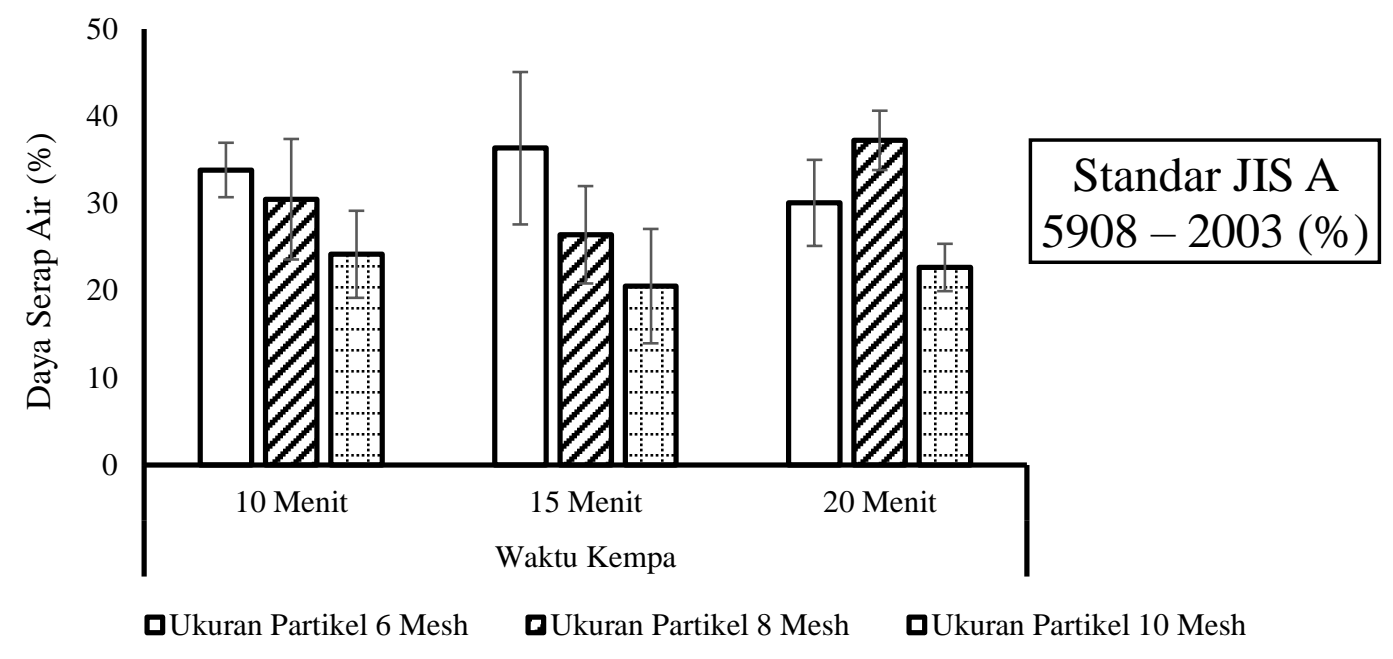

a

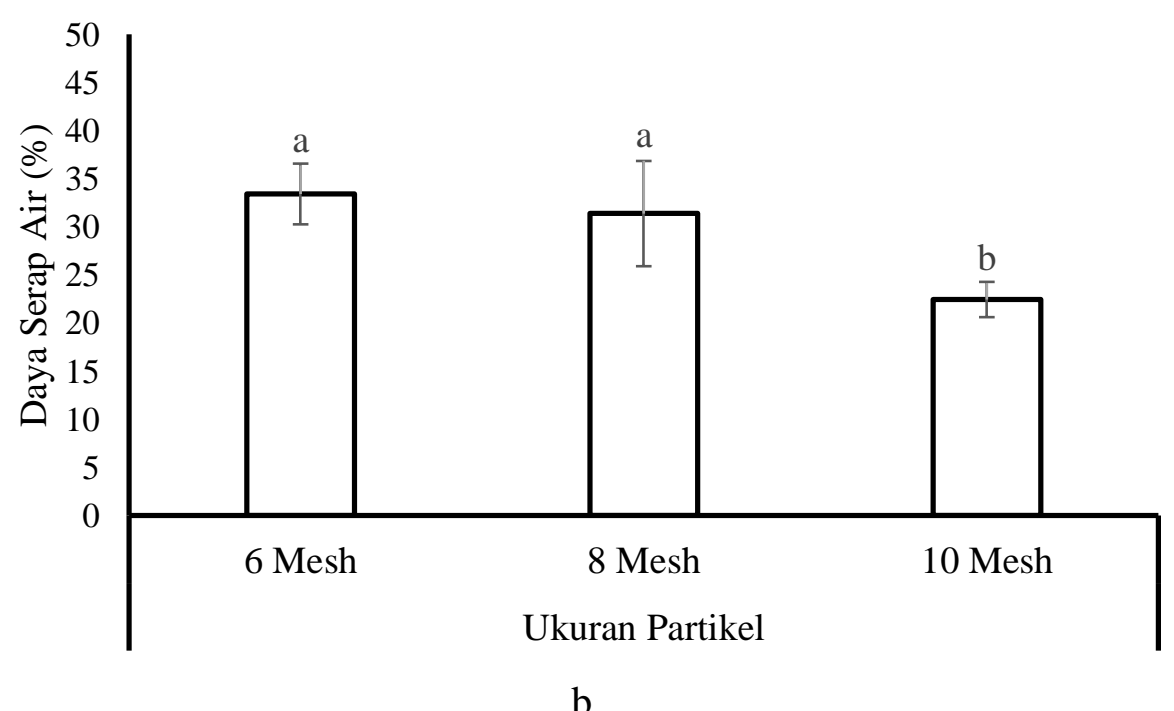

Gambar 3. a. Daya serap air \pm SD papan komposit berdasarkan ukuran partikel dan waktu kempa serta; b. Uji Beda Nyata untuk pengaruh perlakuan ukuran partikel ( $a$. Water absorption $\pm S D$ composite board based on particle size and pressing time; $b$. Real Difference Test for particle size treatment effects)

Hasil penelitian nilai daya serap air menyatakan bahwa semakin kecil ukuran partikel maka nilai daya serap air pada papan komposit semakin kecil (Gambar 3a). Berdasarkan hasil uji BNJ daya serap air menunjukkan bahwa perlakuan ukuran partikel 6 mesh dan 8 mesh tidak berbeda nyata, tetapi berbeda nyata terhadap perlakuan 10 mesh (Gambar 3b). Hal ini diduga karena pada penelitian ini mengunakan bahan plastik sebagai perekat untuk memenuhi rongga 
yang terdapat pada papan komposit, dikarenakan bahan plastik dapat mengurangi penyerapan air ke dalam rongga. Tingginya daya serap air yang masuk diduga pada plastik polipropilena yang melapisi bagian luar papan komposit terangkat saat dilepaskan dari plat seng maka dari itu air dapat mudah masuk saat direndam. Walaupun plastik polipropilena daur ulang yang digunakan sebagai perekat bersifat hidrofobik, namun karena bahan yang digunakan berukuran partikel cukup besar maka kemungkinan tidak seluruh bahan tertutup oleh perekat, apalagi proses pencampuran dilakukan secara manual dengan demikian air masih dapat masuk melalui rongga - rongga sel yang tidak tertutup oleh plastik polipropilena (Setyawati et al. 2008). Hal ini berbanding terbalik dengan pernyataan Abdurachman dan Hadjib (2011) menyatakan papan partikel halus memiliki luas permukaan yang semakin besar dibandingkan dengan partikel kasar, luas permukaan yang besar maka memperbesar kontak dengan air sehingga penyerapan air akan semakin meningkat.

d. Pengembangan Tebal

Secara keseluruhan nilai pengembangan tebal papan komposit yang dihasilkan dapat memenuhi standar JIS A 5908 - 2003 yang mensyaratkan nilai pengembangan tebal papan komposit maksimal 12\%. Nilai pengembangan tebal untuk setiap perlakuan berkisar antara 3,2563 $8,2356 \%$. 


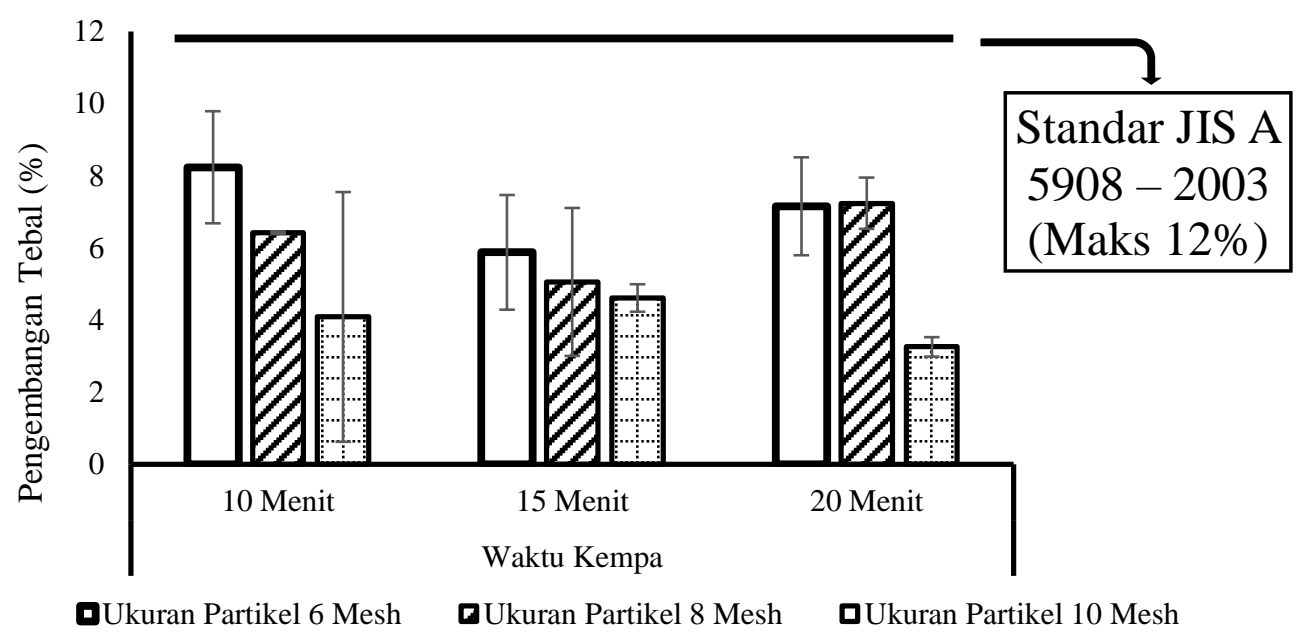

a

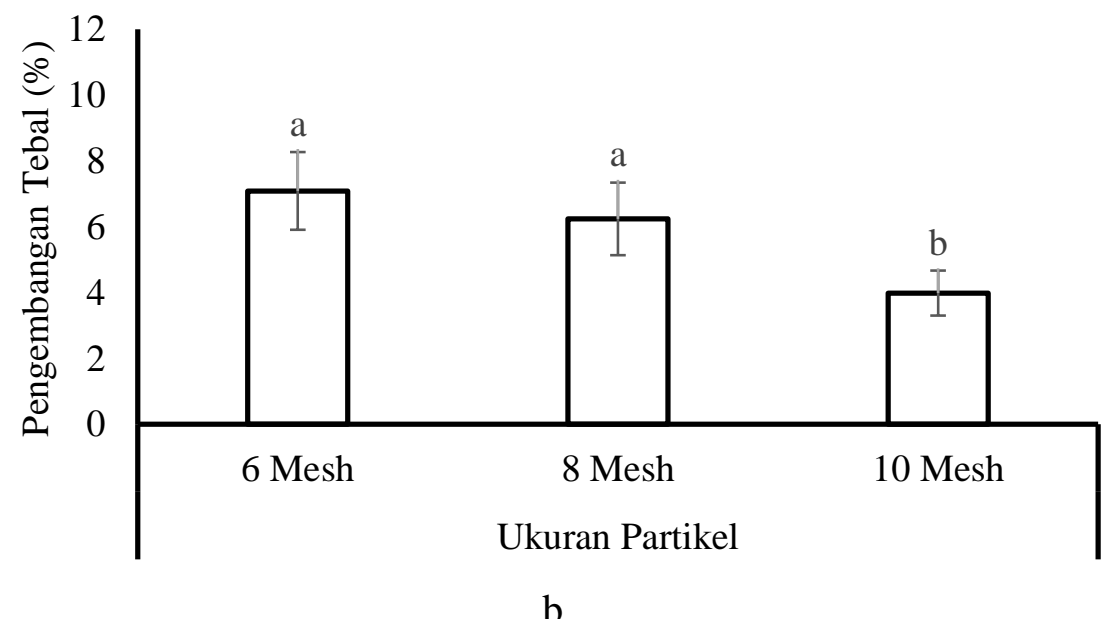

Gambar 4. a. Pengembangan tebal \pm SD papan komposit berdasarkan ukuran partikel dan waktu kempa serta; b. Uji Beda Nyata untuk pengaruh perlakuan ukuran partikel (a. Development of thick composite \pm SD boards based on particle size and time of press and; $b$. Real Difference Test for particle size treatment effects)

Pada hasil penelitian nilai pengembangan tebal ini semakin kecil ukuran partikel maka pengembangan tebalnya semakin kecil (Gambar 4a). Hasil uji BNJ pengembangan tebal berdasarkan ukuran partikel menunjukkan bahwa perlakuan ukuran partikel 6 mesh dan 8 mesh tidak berbeda nyata, tetapi berbeda nyata dengan perlakuan ukuran partikel 10

mesh (Gambar 4b). Menurut Setyawati (2008), faktor utama yang berpengaruh terhadap pengembangan tebal adalah daya serap air. Diduga nilai hasil pengembangan tebal akan selaras dengan nilai daya serap air dimana pada kedua pengujian tersebut menyatakan bahwa ukuran partikel yang kecil akan menghasilkan nilai pengujian yang tidak tebal. Rendahnya nilai 
pengembangan tebal papan komposit karena perekat yang digunakan adalah plastik yang bersifat hidrofobik, sehingga papan komposit yang dihasilkan lebih tahan terhadap air (Zheng, 1995 dalam Setyawati, 2008).

\section{Sifat Mekanik Papan Komposit}

a. Keteguhan Lentur (MOE)

Secara keseluruhan nilai MOE papan komposit yang dihasilkan tidak dapat memenuhi standar JIS A 5908 - 2003, tetapi hanya pada pengujian 8 mesh dengan waktu kempa 10 menit dapat memenuhi standar JIS A 5908 - 2003 yang mensyaratkan nilai MOE papan komposit minimal $20400 \mathrm{~kg} / \mathrm{cm}^{2}$. Nilai Modulus of Elasticity (MOE) untuk setiap perlakuan berkisar antara 9243,1603 - 23725,0499 $\mathrm{kg} / \mathrm{cm}^{2}$.

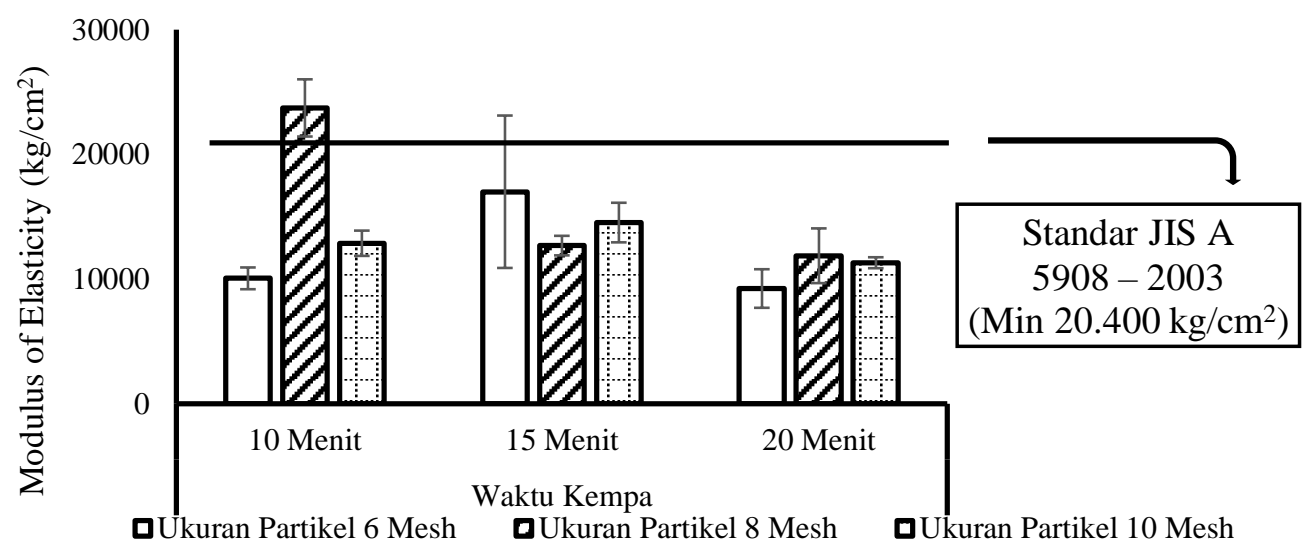

a

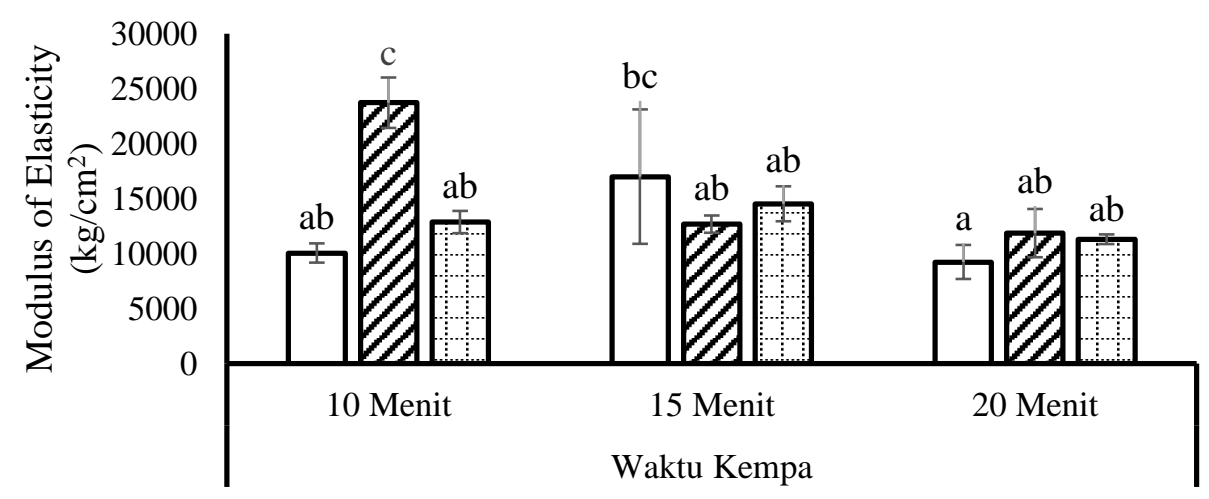

口Ukuran Partikel 6 Mesh ■Ukuran Partikel 8 Mesh ĐUkuran Partikel 10 Mesh

b

Gambar 5. a. MOE \pm SD papan komposit berdasarkan ukuran partikel dan waktu kempa serta; b. Uji Beda Nyata untuk pengaruh perlakuan interaksi ukuran partikel dan waktu kempa (a. MOE $\pm S D$ composite board based on particle size and time of press and; $b$. Real Difference Test for treatment effects of particle size interactions and press time) 
Pada penelitian ini secara keseluruhan nilai MOE tidak memenuhi standar JIS A 5908 - 2003 kecuali pada perlakuan papan 8 mesh dengan waktu 10 menit (Gambar 5a). Berdasarkan hasil uji BNJ menunjukkan bahwa pada perlakuan ukuran partikel 6 mesh dengan waktu kempa 20 menit tidak berbeda nyata dengan keseluruhan perlakuan kecuali perlakuan 6 mesh dengan waktu kempa 15 menit dan 8 mesh dengan waktu kempa 10 menit mempunyai pengaruh yang berbeda nyata. Pada perlakuan 8 mesh dengan waktu kempa 10 menit berbeda nyata dengan keseluruhan perlakuan kecuali perlakuan 6 mesh dengan waktu kempa 15 menit (Gambar 5b). Diduga papan tidak memenuhi standar karena tidak adanya penahan pada permukaan papan komposit sehingga pada saat diberi beban, bagian papan yang menerima beban tekan dan tarik adalah pada bagian permukaan papan komposit dengan tidak adanya lapisan maka kemampuan papan komposit untuk menahan beban tersebut menjadi lebih kecil. Pada penelitian ini lebih kecil jika dibandingkan dengan penelitian sebelumnya mengenai papan komposit yang mengunakan bahan serat kulit batang sagu dan plastik polipropilena (Umam et al. 2017), dikarenakan pada penelitian sebelumnya mengunakan lapisan finir dan bambu, bahan pelapis pada permukaan papan komposit tersebut dapat menahan beban, sebab sifat mekanik finir dan bambu yang tinggi. Penelitian tersebut sejalan dengan penelitian Suhasman et al. (2005) yang menyatakan penambahan bahan pelapis pada papan komposit dapat meningkatkan kekuatan papan.

b. Keteguhan Patah (MOR)

Secara keseluruhan nilai MOR papan komposit yang dihasilkan dapat memenuhi standar JIS A 5908 - 2003 yang mensyaratkan nilai MOR papan komposit minimal $80 \mathrm{~kg} / \mathrm{cm}^{2}$. Nilai Modulus of Rapture (MOR) untuk setiap perlakuan berkisar antara 3682,2226 $5172,2443 \mathrm{~kg} / \mathrm{cm}^{2}$ (Gambar 6a). Berdasarkan hasil uji BNJ menunjukkan bahwa pada perlakuan ukuran partikel 6 mesh dengan waktu kempa 20 menit tidak berbeda nyata dengan keseluruhan perlakuan kecuali perlakuan 6 mesh dengan waktu kempa 15 menit dan 8 mesh dengan waktu kempa 10 menit mempunyai pengaruh yang berbeda nyata. Pada perlakuan 8 mesh dengan waktu kempa 10 menit berbeda nyata dengan keseluruhan perlakuan kecuali perlakuan 6 mesh dengan waktu kempa 15 menit (Gambar 6b). 


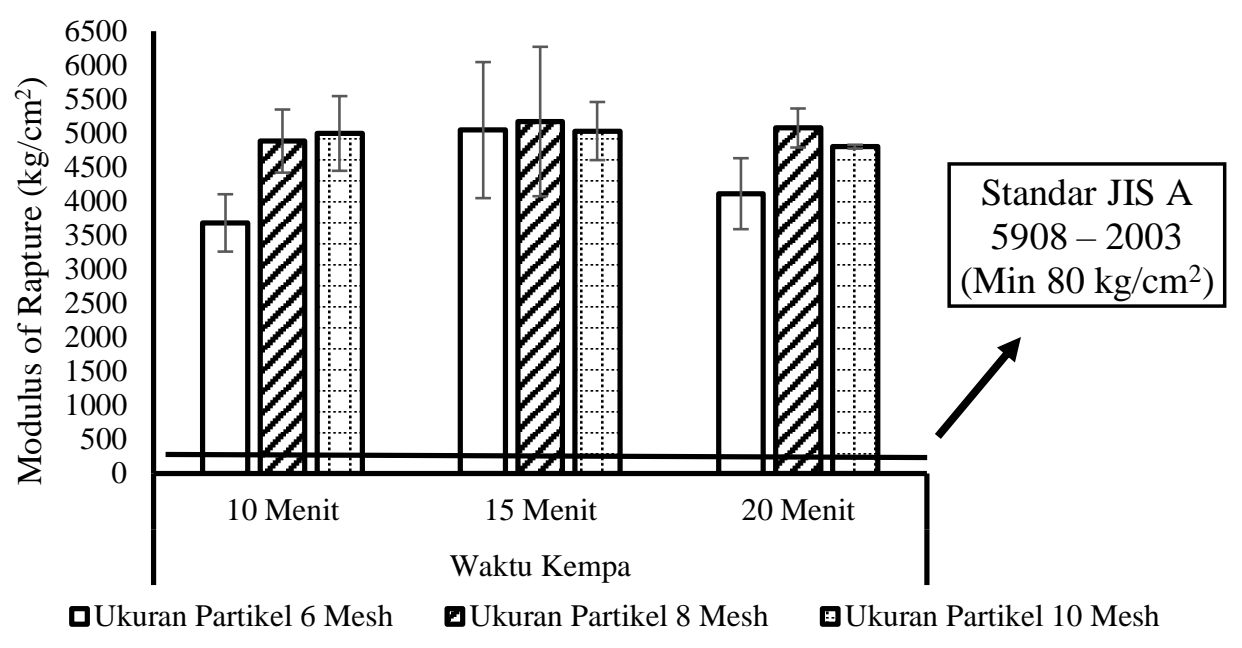

a

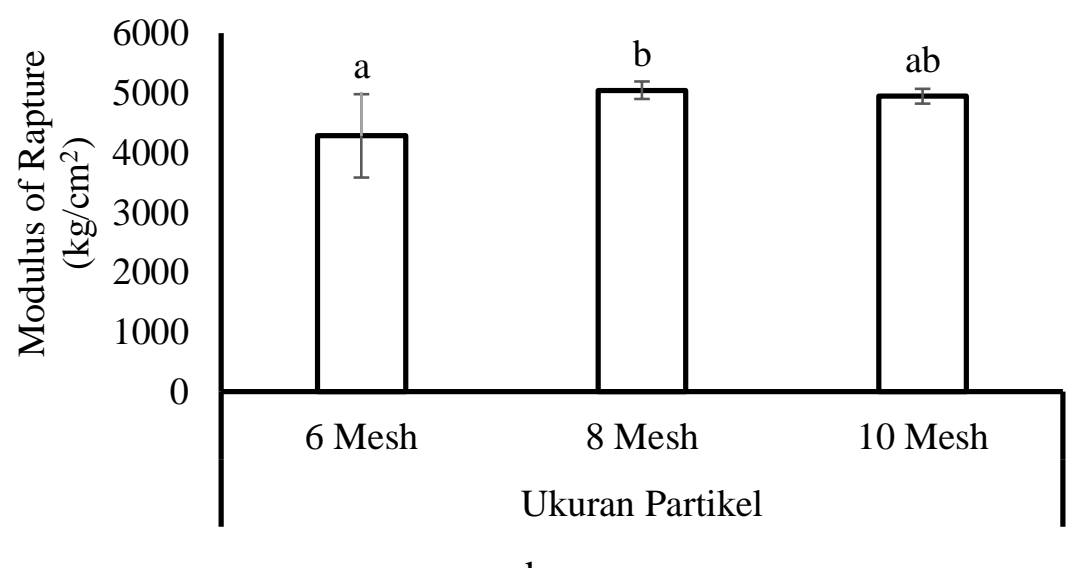

b

Gambar 6. a. MOR \pm SD papan komposit berdasarkan ukuran partikel dan waktu kempa serta; b. Uji Beda Nyata untuk pengaruh perlakuan ukuran partikel ( $a$. MOR $\pm S D$ composite board based on particle size and time of press and; $b$. Real Difference Test for particle size treatment effects)

Hasil penelitian ini memiliki nilai MOR yang lebih tinggi dibandingkan dengan penelitian sebelumnya yang dilakukan Aminah et al. (2018) mengenai papan partikel yang terbuat dari Acacia crassiacarpa yang memiliki nilai MOR tertinggi $222,9785 \mathrm{~kg} / \mathrm{cm}^{2}$, dikarenakan penelitian ini menggunakan perekat plastik sehingga daya ikat antara partikel lebih kuat dan tidak mudah patah juga sifat plastik polipropilena yang kaku, tidak gampang sobek serta dapat menutupi rongga pada papan komposit (Bost, 1980 dan Syarief et al. 1989). Pendapat ini sejalan dengan Maloney (1993) yang mengatakan bahwa nilai MOR dipengaruhi oleh bahan perekat yang digunakan serta daya ikat perekat dan ukuran partikel.

c. Keteguhan Rekat (IB) 
Secara keseluruhan nilai IB papan komposit yang dihasilkan dapat memenuhi standar JIS A 5908 - 2003 yang mensyaratkan nilai IB papan komposit minimal $1,5 \mathrm{~kg} / \mathrm{cm}^{2}$. Berdasarkan nilai keteguhan rekat (Internal Bonding/IB) untuk setiap perlakuan berkisar antara $5,6580-$
10,2656 $\mathrm{kg} / \mathrm{cm}^{2} \quad$ (Gambar 7a). Berdasarkan hasil uji BNJ menunjukkan bahwa perlakuan waktu kempa 10 menit berbeda nyata dengan perlakuan waktu kempa 20 menit, sedangkan parlakuan waktu kempa 15 menit tidak berbeda nyata terhadap perlakuan waktu kempa 10 menit dan 20 menit (Gambar 7b).

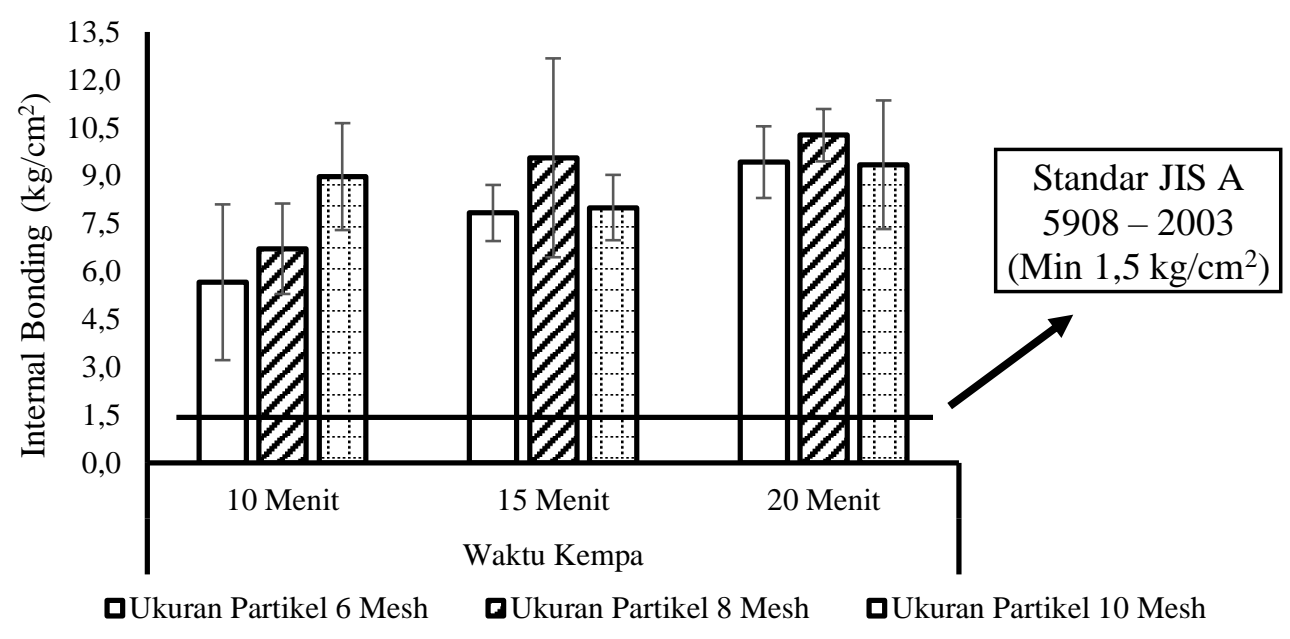

a

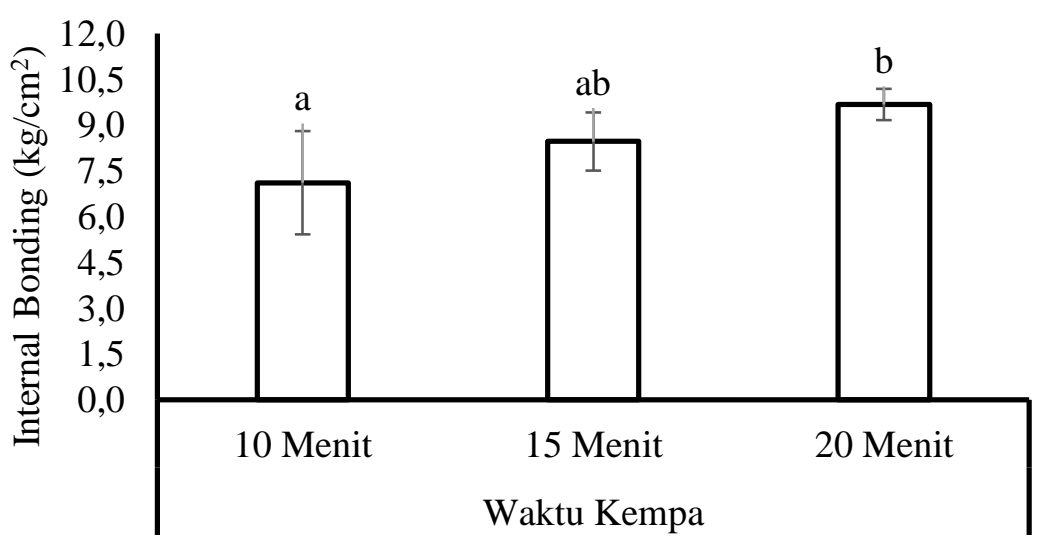

b

Gambar 7. a. Internal Bonding \pm SD papan komposit berdasarkan ukuran partikel dan waktu kempa serta; b. Uji Beda Nyata untuk pengaruh perlakuan waktu kempa (a. Internal bonding $\pm S D$ composite board based on particle size and time of press and; $b$. Significant Difference Test for felting time treatment effects) 
Pada penelitian ini keseluruhannya memenuhi standar JIS A 5908 - 2003, diduga papan komposit memiliki daya serat yang baik sehingga pada setiap rongga memiliki kekuatan rekat yang kuat ditambah lagi dengan daya ikat perekat plastik polipropilena yang dapat membantu daya ikat antar partikel, karena plastik memiliki sifat yang kaku dan tidak gampang sobek maka pada pengujian internal bonding memiliki hasil yang tinggi. Hasil penelitian ini lebih tinggi dari pada penelitian sebelumnya yang dilakukan oleh Riki et al. (2018) yang memiliki nilai tertinggi pada pengujian Internal Bonding 3,3861 $\mathrm{kg} / \mathrm{cm}^{2}$ yang mengunakan bahan limbah finir Albizia falcataria dan Paraserianthes falcataria berdasarkan perlakuan jumlah lapisan dan kerapatan menggunakan perekat Urea Formaldehida. Hal ini menunjukkan bahwa kekuatan rekat inti papan komposit yang menggunakan bahan perekat polipropilena lebih besar dari pada kekuatan rekat inti dengan bahan perekat Urea Formaldehida.

d. Kuat Pegang Serup

Secara keseluruhan nilai kuat pegang sekrup papan komposit yang dihasilkan dapat memenuhi standar JIS A 5908 - 2003 yang mensyaratkan nilai kuat pegang sekrup papan komposit minimal $30 \mathrm{~kg}$. Nilai kuat pegang sekrup untuk setiap perlakuan berkisar antara 92,4589 - 120,6825 kg (Gambar 8a). Berdasarkan hasil uji BNJ menunjukkan bahwa perlakuan ukuran partikel 6 mesh berbeda nyata dengan perlakuan ukuran partikel 8 mesh, sedangkan parlakuan ukuran partikel 10 mesh tidak berbeda nyata terhadap perlakuan ukuran partikel 6 mesh dan 8 mesh (Gambar 8b) 


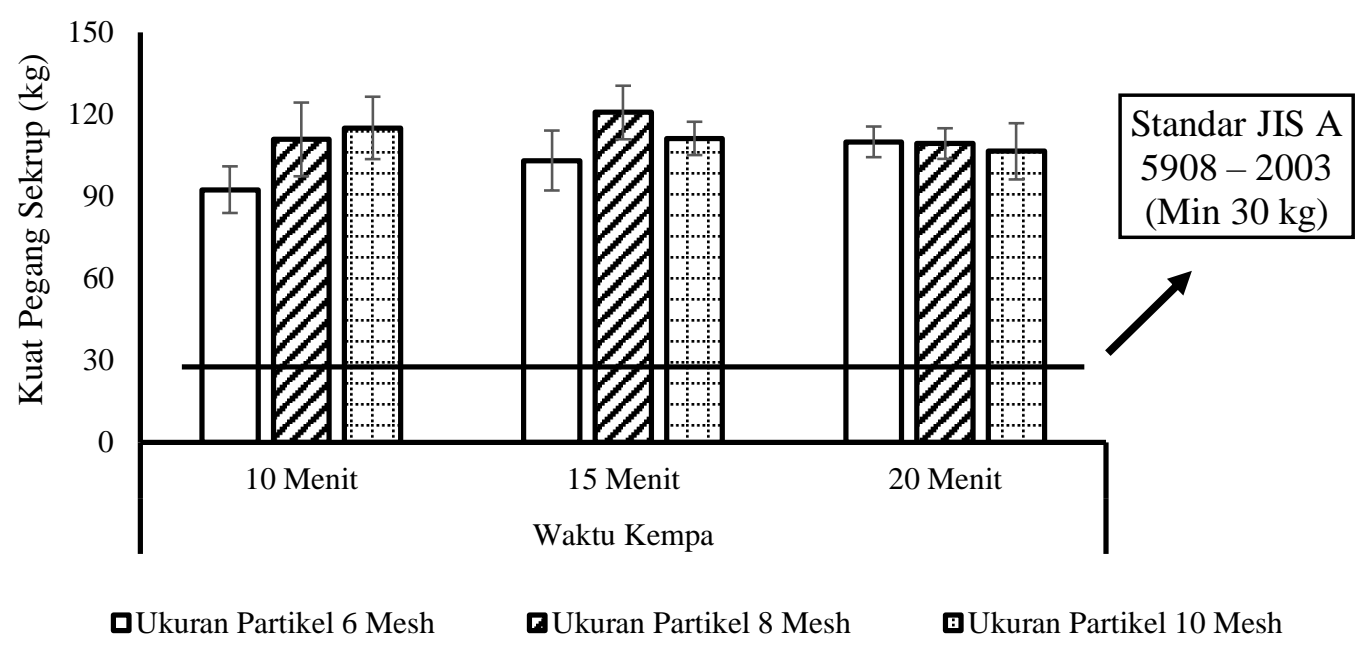

a

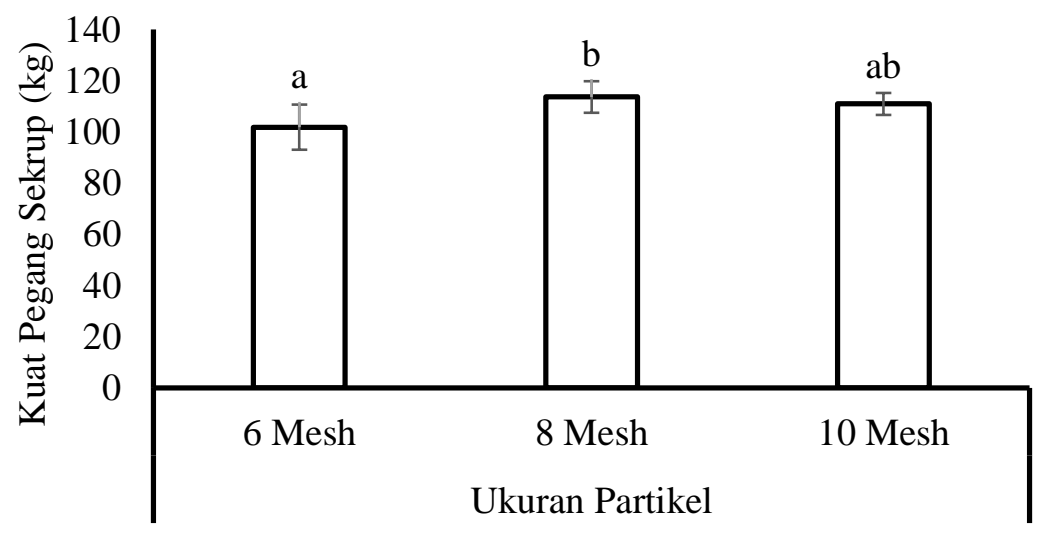

b

Gambar 8. a. Kuat pegang sekrup \pm SD papan komposit berdasarkan ukuran partikel dan waktu kempa serta; b. Uji Beda Nyata untuk pengaruh perlakuan ukuran partikel (a. Strength of holding screws $\pm S D$ composite boards based on particle size and press time and; $b$. Real Difference Test for particle size treatment effects)

Pada hasil penelitian ini menunjukkan bahwa secara keseluruhan memenuhi standar JIS A 5908 - 2003. Pada penelitian ini menggunakan bahan perekat plastik sehingga daya rekat terhadap papan komposit menjadi lebih kuat dan kaku sehingga bahan perekat mempu menutupi rongga pada setiap perlakuan ukuran partikel pada suhu $180^{\circ} \mathrm{C}$ dengan tekanan $\pm 25 \mathrm{~kg} / \mathrm{cm}^{2}$, sehingga dapat meratakan perekat pada ikatan antar partikel. Menurut Haygreen dan Bowyer (1993), kekuatan menahan sekrup terutama ditentukan oleh kerapatan papan. Walaupun kerapatan papan komposit pada penelitian ini relatif sama adanya perbedaan ukuran partikel dan lamanya waktu pengempaan dapat mempengaruhi kemampuan papan komposit dalam menahan sekrup. Hasil 
penelitian ini dalam pengujian kuat pegang sekrup sama baiknya dengan penelitian sebelumnya yang dilakukan oleh Idawati (2014) yang memiliki hasil berkisar dari 79,91 - 125,03 kg, menggunakan bahan batang kelapa sawit dan plastik polipropilena berdasarkan variasi rasio dan penambahan maleic anhydrid. Nilai kuat pegang sekrup yang memadai sangat penting dalam pengerjaan papan seperti dalam pembuatan mebel yang membutuhkan sekrup atau paku sebagai pengencang sambungan (Setyawati et al. 2008).

\section{Kesimpulan}

1. Faktor ukuran partikel berpengaruh terhadap perlakuan uji kerapatan, daya serap air, pengembangan tebal, MOE, MOR dan kuat pegang sekrup. Adapun pada faktor waktu kempa berpengaruh terhadap perlakuan uji MOE dan internal bonding. Namun pada pengujian kadar air tidak berpengaruh nyata terhadap faktor ukuran partikel dan waktu kempa. Faktor interaksi antara ukuran partikel dan waktu kempa terdapat pengaruh sangat nyata pada perlakuan uji MOE.

2. Pada penelitian ini yang memenuhi standar JIS A 5908 - 2003 adalah kerapatan, daya serap air, pengembangan tebal, MOR, internal bonding, kuat pegang sekrup. Sedangkan pada pengujian kadar air dan MOE tidak memenuhi standar JIS A 5908 - 2003. Perlakuan terbaik yang memenuhi standar JIS A 5908 - 2003 untuk keseluruhan pengujian papan komposit adalah perlakuan ukuran partikel 8 mesh dengan waktu kempa 15 menit.

\section{Saran}

Secara keseluruhan papan komposit tidak berpengaruh yang dihasilkan nyata terhadap faktor perlakuan waktu kempa kecuali pada pengujian internal bonding. Oleh karena itu disarankan untuk penelitian selanjutnya dapat mencari faktor perlakuan lain seperti berdasarkan penambahan compatibilizer dan penambahan lapisan pada papan komposit.

\section{DAFTAR PUSTAKA}

Abdurachman, Hadjib N. 2011. Sifat papan partikel dari kayu kulit manis (Cinnamomum burmanii BL). Penelitian Hasil Hutan 29 (2) : $128-141$.

Aminah, Setyawati D, Ahmad Yani. 2018. Sifat Fisik Dan Mekanik Papan Partikel Dari Limbah Kayu Acacia crassicarpa Pada Beberapa Ukuran Partikel Dan Konsentrasi Urea Formaldehida. Jurnal Hutan Lestari. 6 (3) : 557 - 568.

Erniwati, Hady Y, Massijaya M, Nugroho N. 2008. Pengaruh Suhu Dan Waktu Kempa Terhadap Kualitas Papan Komposit Berlapis Anyaman Bambu. Jurnal Fakultas Kehutanan Unmul. 13 (2) : 106 111.

Haygreen JG, Bowyer JL. 1993. Forets Products and Wood Science An Introduction. The lowa State University Press, Ames. IOWA.

Idawati, Setyawati D, Nurhaida, Diba F. 2014. Kualitas Papan Komposit dari Batang Kelapa Sawit (Elaeis guneensis Jacq) dan Limbah 
Plastik Polipropilena Pada Beberapa Variasi Rasio dan Penambahan Maleic Anhydride (MAH). Jurnal Hutan Lestari. 2 (3) : 546-554.

JIS A 5908 - 2003. Particleboard. Japanese Industrial Association. Japan.

Kementerian Kehutanan. 2013. Rencana Kerja Tahun 2014 Kementerian Republik Indonesia. Biro Perencanaan Kementerian Kehutanan. Tahun 2013. Jakarta.

Maloney TM. 1993. Modern Particle Board and Dry Process Fiberboard Manufacturing. San Fransisco:Miller Freeman, inc.

Massijaya MY, Tambunan B, Hadi YS, Bakar ES, dan Sunami I. 1999. Studi Pembuatan Papan Partikel dari Limbah Kayu dan Plastik Polystyrene. Jurnal Teknologi Hasil Hutan.12 (2) : 299-308.

Maulana D, Dirhamsyah, Setyawati D. 2015. Karakteristik Papan Partikel Dari Batang Mengkuang (Pandanus atrocarpus Griff) Berdasarkan Ukuran Partikel dan Konsentrasi Urea Formaldehida. Jurnal Hutan Lestari. 3(2): 247 258.

Purwaningrum P. 2016. Upaya Mengurangi Timbulan Sampah Plastik di Lingkungan. Jurusan Teknik Lingkungan, FALTL, Universitas Trisakti, Jakarta. Indonesia.

Riki, Dirhamsyah M, Setyawati D. 2018. Sifat Fisik - Mekanik Papan Partikel dari Limbah Finir Berdasarkan Jumlah Lapisan dan Kerapatan. Jurnal Hutan Lestari. 6 (4) : $720-732$.
Setyawati D, Yusuf SH, M Yusram M, Naresworo N. 2008. Karakteristik Papan Komposit dari Serat Sabut Kelapa dan Plastik Polipropilena Daur Ulang Berlapis Anyaman Bambu. Jurnal Ilmu dan Teknologi Hasil Hutan. 1 (1) : 18 - 26.

Sinaga JL, Sulaeman R, Sribudiani E. 2016. Pemanfaatan limbah serbuk kayu mahang (Macaranga sp.) dengan penambahan cangkang kakao (Theobroma cacao L.) menjadi briket sebagai bahan bakar alternatif. Jurnal Jom Faperta 3. (1).

Suhasman, Massijaya MY, Hadi YS. 2005. The effect of face and back layer types on composite board quality In: Dwianto $\mathrm{W}$, editor. Towards Ecology and Economy Harmonization of Tropical Forest Resources. Proceeding of the $6^{\text {th }}$ International Wood Science Symposium LIPI-JSPS Core University in Field of Wood Science. August 29-31 2005. Bali Indonesia.

Sumimi, Farahdiba, Nurhaida, Setiawaty D. 2016. Kualitas Papan Komposit Kulit Batang Sagu (Metroxylon sp) dan Limbah Plastik Polipropilena Berdasarkan Penambahan Compatibilizer. Jurnal Hutan Lestari. 4 (4) :570-579.

Umam T, Setyawati D, Farahdiba. 2017. Kualitas Papan Komposit Serat Kulit Batang Sagu dan Plastik Polipropilena (PP) berlapis Finir dan Bambu. Jurnal Hutan Lestari. 5 (4) : $942-951$. 